\title{
The Lipids of the Common House Crickat, Acheta domesticus L. II. Hydrocarbons
}

RODERICK F. N. HUTCHINS ${ }^{1}$ and MICHAEL M. MARTIN, ${ }^{2}$ Depart thent of Chemistry, University of Michigan, Ann Arbor, Michigan 48104

\section{ABSTRACT}

The hydrocarbons of the common house cricket Acheta domesticus L. consist of $n$ alkanes $(4 \%)$, 2-methylalkanes $(20 \%)$, $\mathrm{x}$-methylalkanes $(59 \%)$, an unidentified series of alkanes (trace), and olefins (16$18 \%)$. The major $n$-alkane is $n$-nonacosane $(3.5 \%)$. The major 2-methylalkanes are 2-methyloctacosane $(8 \%)$ and 2methyltriacontane $(11 \%)$. The members of the homologous $\mathrm{x}$-methylalkane series consist of mixtures of methylalkanes in which the methyl side-chain is located on the $13 \mathrm{th}, 15 \mathrm{th}$, and $17 \mathrm{th}$ carbon atom in the chain. The major $\mathrm{x}$-methylalkanes are the homologues containing $31(3 \%), 33$ $(6.5 \%), 35(12.5 \%), 37(27 \%)$, and 39 $(2.5 \%)$ carbon atoms. The olefins are a mixture of straight-chain and 2-methylalkenes and alkadienes. The major olefins contain $31(3 \%)$ and $37(7.5 \%)$ carbon atoms.

\section{INTRODUCTION}

$\mathrm{T}$ HE ADVENT OF analytical and preparative gas-liquid chromatography (GLC), coupled with mass spectral techniques, has permitted detailed analyses of naturally occurring hydrocarbon mixtures heretofore considered beyond the realm of possibility. Whereas early studies of the hydrocarbon constituents of various plant and insect waxes had succeeded in recognizing the presence of an homologous series of alkanes, usually characterized as predominantly odd carbon-numbered normal alkanes in the 27 to 33 carbon range, more recent studies have demonstrated a much greater degree of complexity.

Even-numbered as well as odd-carbon-numbered alkanes, alkenes, alkadienes, monomethylalkanes with the methyl side-chain located at a number of different positions, di-

\footnotetext{
${ }^{1}$ Postdoctoral Research Associate. Department of Chemistry, University of Michigan, 1965-1967.

2 Associate Professor. Department of Chemistrv, University of Michigan; Alfred P. Sloan Foundation Fellow, to whom inquiries regarding this publication should be addressed.
}

methylakanes, highly branched alkanes, and cycloalkanes have now been recognized as significant components of a number of natural waxes $(1-10)$. By far the most thorough study of a naturally occurring hydrocarbon mixture has been by Mold et al. $(11,12)$, who utilized the hydrocarbon fraction of wool wax. They have characterized 93 components of a hydrocarbon fraction, which constitutes only $32 \%$ of the total hydrocarbons present.

The characterization of the hydrocarbons of insect duticle is of interest for a number of reasons. A knowledge of the constituents of cuticular wax is clearly basic to an understanding of the role of the cuticle in maintaining water balance. Likewise basic to any biochemical study designed to establish the metabolic pathways available for hydrocarbon synthesi is the characterization of the metabolic end-products. Hydrocarbon biosynthesis is an area of lipid metabolism in which little has been done. Robbins et al. (13) and Piek (14) have demonstrated the incorporation of ${ }^{14} \mathrm{C}$ from $1{ }^{-14} \mathrm{C}$ acetate into the hydrocarbons of the wax of Musca domesticus and Apis mellifera ro pectively, but any characterization of the anabolic pathways connecting acetate and the many constituents of the hydrocarbon mixtures present is lacking. Finally chemical taxonomy, utilizing hydrocarbon patterns, promises to be a valuable adjunct to classical morphological taxonomy when applied to large groups of similar and closely related species (7, 15).

This paper discusses the characterization of the hydipcarbons of the common house cricket. Achera domesticus L. As a consequence of the relalive ease of maintaining laboratory colonies $(16,17)$ and because of its commercial availability, $A$. domesticus is an attractive species for chemical, biochemical, and biological studiks.

\section{MATERIALS AND METHODS}

\section{Isolation of the Hydrocarbon Fraction}

In a ypical run, $5.0 \mathrm{~g}$ of lipid extract, obtained an described in the previous paper (18), was adserbed onto a column of $400 \mathrm{~g}$ of Flori- 
sil (Fisher) to which $28 \mathrm{~g}$ of water had previously been added (19). A hydrocarbon fraction weighing $290 \mathrm{mg}$ was eluted with petroleum ether $(40-60 \mathrm{C}$, redistilled). This hydrocarbon fraction showed no absorption in its infrared spectrum characteristic of a carbenyl or hydroxyl function.

\section{Separation of Saturated from Unsaturated Hydrocarbons (20)}

In this and all subsequently described operations anhyrous reagent grade ether and redistilled reagent grade petroleum ether were utilized. The glassware was carefully cleaned. In a typical run $1.15 \mathrm{~g}$ of cricket hydrocarbons was placed on a column of $50 \mathrm{~g}$ of silica gel, impregnated with $25 \%$ silver nitrate (Adsorbosil-CABN, Applied Science Laboratories). Saturated hydrocarbons $(0.97 \mathrm{~g})$ were eluted with petroleum ether, unsaturated hydrocarbons $(0.19 \mathrm{~g})$ with ether: petroleum ether $(10: 90)$. Infrared spectra of both fractions indicated an efficient separation of saturated from unsaturated hydrocarbons.

\section{Hydrogenation of Unsaturated Hydrocarbons}

The unsaturated hydrocarbon fraction $(100$ $\mathrm{mg}$ ), dissolved in $25 \mathrm{ml}$ of acetic acid to which just enough petroleum ether was added to effect solution, was hydrogenated at room temperature and atmospheric pressure for $2 \mathrm{hr}$ using $100 \mathrm{mg}$ of $5 \%$ platinum on carbon (Engelhard Industries Newark, N. J.) as catalyst. The mixture was filtered, water was added, and the hydrogenated product, was extracted with petroleum ether. Removal of the petroleum ether solvent gave a hydrocarbon product devoid of any infrared absorption attributable to a double bond.

\section{GLC Conditions}

The GLC analyses were conducted on a dual column F \& M Model 810 gas chromatograph, equipped with dual flame ionization detectors. Analyses were run isothermally at temperatures between $220 \mathrm{C}$ and $330 \mathrm{C}$ on $6 \mathrm{ft} . \times 1 / 8$ in. o.d. $10 \%$ Apiezon $\mathrm{L}$ on acid-washed silanized Chromosorb W columns. High operating temperatures were advantageous if the analyses were concerned with higher homologues, but lower temperatures were used for the lower homologues.

\section{Determination of Amounts of Each Component}

The relative amounts of the various components in the saturated and unsaturated hydrocarbon mixture were determined by quantitative GLC. The higher homologues in these mixtures gave broad, rounded peaks, and by analyses of prepared mixtures of known composition it was found that the most accurate quantitative data were obtained by cutting out the individual peaks and weighing them. Such a procedure was far superior to triangulation or disc integration. The quantitative data presented in Table $I$ are averages of three or four different determinations run at different temperatures.

\section{Removal of n-Alkanes from an Alkane Mixture}

In order to confirm the identification of the $n$-alkane series in the saturated alkane mixture, $n$-alkanes were removed by treatment with a molecular sieve (Linde, $5 \mathrm{~A}$ ). Those peaks absent from the GLC of a sample so treated corresponded exactly to those which had been identified as $n$-alkanes by comparison with standards and by graphing of the logarithms of retention times against carbon number. In a typical experiment $101 \mathrm{mg}$ of an alkane mixture, from which unsaturates had been removed, was dissolved in $7 \mathrm{ml}$ of isooctane, and the solution was shaken with $6 \mathrm{~g}$ of Linde $5 \mathrm{~A}$ molecular sieves (1/16-in. pellets) overnight. The mixture was then filtered, and the sieves were washed twice with an equal volume of isooctane. The filtrate was concentrated to $7 \mathrm{ml}$, $6 \mathrm{~g}$ of Linde $5 \mathrm{~A}$ molecular sieve were added. and the mixture was shaken for $24 \mathrm{hr}$, after which it was filtered and washed as described previously. Upon concentrating the isooctane filtrates, a hydrocarbon mixture was obtained which contained only the Series II and the Series III alkanes. The largest peaks in the gas chromatogram which were removed were the two with retention times identical to n-octacosane and $n$-nonacosane.

\section{Oxidative Cleavage of the Unsaturated Hydrocarbons (21)}

To a solution of $135 \mathrm{mg}$ of unsaturated hydrocarbons in $50 \mathrm{ml}$ of $t$-butyl alcohol was added a solution of $600 \mathrm{mg}$ of sodium periodate and $40 \mathrm{mg}$ of potassium permanganate dissolved in $50 \mathrm{ml}$ of water. The $\mathrm{pH}$ of the mixture was adjusted to 8-9 by the addition of aqueous potassium carbonate, then the solution was stirred for four days. The solution was extracted with methylene chloride to remove any neutral materials, of which there appeared to be none. The aqueous solution was then decolorized and neutralized with an aqueous solution of sodium bisulfite and extracted with chloroform. The chloroform solution was dried over sodium sulfate, filtered, and evaporated to dryness, leaving $117 \mathrm{mg}$ of acids. This residue was esterified using boron trifluoride/ 
TABLE I

The Hydrocarbons of the Common House Cricket, Acheta domesticus L., Percentage Composition ${ }^{a}$

\begin{tabular}{|c|c|c|c|c|c|}
\hline $\begin{array}{l}\text { Carbon } \\
\text { Number }\end{array}$ & $\begin{array}{c}\text { Series I } \\
\text { (n-alkanes) }\end{array}$ & $\begin{array}{l}\text { Series II } \\
\text { (2-methyl- } \\
\text { alkanes) }\end{array}$ & $\begin{array}{l}\text { Series III } \\
\text { (x-methyl- } \\
\text { alkanes) }\end{array}$ & $\begin{array}{c}\text { Series IV } \\
\text { (unidentified) }\end{array}$ & (Olefins) \\
\hline 15 & Trace & Trace & - & Trace & - \\
\hline 16 & Trace & Trace & - & Trace & - \\
\hline 17 & Trace & Trace & - & Trace & - \\
\hline 18 & Trace & Trace & 一 & Trace & Trace \\
\hline 19 & Trace & Trace & - & Trace & Trace \\
\hline 20 & Trace & Trace & 一 & Trace & Trace \\
\hline 21 & Trace & Trace & - & - & Trace \\
\hline 22 & Trace & Trace & - & - & Trace \\
\hline 23 & Trace & Trace & - & - & Trace \\
\hline 24 & Trace & Trace & 一 & - & Trace \\
\hline 25 & Trace & Trace & - & - & Trace \\
\hline 26 & Trace & Trace & - & - & Trace \\
\hline 27 & Trace & Trace & Trace & - & Trace \\
\hline 28 & $<0.5$ & Trace & 一 & - & Trace \\
\hline 29 & 3.5 & 8.0 & Trace & - & 1.5 \\
\hline 30 & Trace & 0.5 & Trace & - & $<0.5$ \\
\hline 31 & - & 11.5 & 3.0 & - & 3.0 \\
\hline 32 & - & - & 0.5 & - & Trace \\
\hline 33 & - & 0.5 & 6.5 & - & $1.0^{\mathrm{b}}$ \\
\hline 34 & - & - & 1.5 & - & Trace \\
\hline 35 & 一 & - & 12.5 & - & $0.5^{c}$ \\
\hline 36 & - & - & 4.0 & - & $<0.5$ \\
\hline 37 & - & — & 27.0 & - & $7.5^{\mathrm{d}}$ \\
\hline 38 & - & - & 1.5 & - & 1.5 \\
\hline 39 & - & - & 2.5 & - & 1.5 \\
\hline Total \% & 4.0 & 20.5 & 59.0 & Trace & 17.5 \\
\hline
\end{tabular}

Accurate to 2-3 absolute percentage for components present to the extent of $3 \%$ or more. Percentages for minor components have a larger error associated with them.

b Three overlapping peaks on GLC, one minor and two of equal magnitude.

c Two overlapping peaks of equal magnitude on GLC.

'Two peaks on GLC, one very minor, the other major $(>97 \%)$.

methanol (22) and analyzed by GLC with the use of 6 -ft. $\times 1 / 8$-in O.D. $6 \%$ LAC 728 columns.

\section{RESULTS AND DISCUSSION}

In Table $\mathrm{I}$ is presented the distribution of the cricket hydrocarbons. The weight percentage composition values have been rounded off to the nearest half per cent. Those components designated as "trace" constituents were clearly identifiable peaks on the gas-liquid chromatograms and fit nicely onto the logarithmic plots but were so minor as to make any attempt at quantitation pointless.

The hydrocarbon mixture initially obtained from the crickets was subdivided into a saturated and an unsaturated fraction by column chromatography on silica gel impregnated with silver nitrate. GLC of the saturated hydrocarbon fraction indicated a complex mixture. However, by plotting the logarithm of the retention times of the various components against a linear ordinate representing the number of carbon atoms present in the hydrocarbon, three parallel lines resulted, indicating that the saturated hydrocarbon mixture consists of three homologous series, designated Series I, II, and III. $^{3}$

Series I was identified as homologous normal alkanes; every carbon number from 15 to 30 was represented although most of them were only in trace amounts. The line resulting from the logarithmic plot coincided precisely with one constructed from authentic reference samples. Furthermore the two major components of the Series I hydrocarbons had retention times on GLC identical to authentic n-octacosane and $n$-nonacosane. Treatment of the saturated hydrocarbon mixture with the Linde 5 A molecular sieve completely removed all of the components present in Series I. These hydrocarbons are therefore normal alkanes. The

\footnotetext{
"Authentic samples utilized for direct comparison and for the construction of logarithmic plots included $n$-hexane $n$-octane, $n$-decane, $n$-tetradecane, and $n$-hexadecane (F \& M Scientific Corporation); $n$-octadecane and $n$-tetracosane (Applied Science Laboratories); n-octacosane, $n$-dotriacontane, and $n$-hexatriacontane (Aldrich Chemical Company); n-nonacosane and $n$-hentriacontane (donated by $E$. Ritchie, Department of Organic Chemistry, University of Sydney, Sydney, Australia); 2-methyltricosane, 2-methyloctacosane, 3-methyltetracosane, and 12-methylnonacosane (donated by James Mold, Research Department, Liggett and Myers Tobacco Company, Durham, N. C.).
} 
$n$-alkanes, which so often constitute the bulk of naturally occurring hydrocarbon mixtures, make up only $4 \%$ of the hydrocarbons of Acheta domesticus $\mathrm{L}$.

Series II was identified as homologous 2methylalkanes (isoalkanes). An authentic sample of 2-methyloctacosane had a retention time identical to the 29-carbon Series II hydrocarbon. An authentic sample of 3-methyltetracosane had a different retention time from the trace Series II component with 25 carbons. Also, a mass spectrum of the saturated hydrocarbon mixture had parent peaks at 408 and 436 mass units, corresponding to $\mathrm{C}_{29} \mathrm{H}_{2 n}$ and $\mathrm{C}_{21}$ $\mathbf{H}_{64}$ hydrocarbons (the two major Series II alkanes); large fragment peaks at 393 and 421, corresponding to the loss of 15 mass units; a methyl group from each of parent ions but not fragment peaks at 379 and 407 , which would have resulted from the loss of 29 mass units; an ethyl group from the parent ions of 3methyloctacosane and 3-methyltriacontane. Thus it can be concluded that the Series II hydrocarbons are 2-methylalkanes (isoalkanes) and that 3-methylalkanes (anteisoalkanes) are absent from the hydrocarbon mixture. The isoalkanes, a class of hydrocarbons which is being encountered more and more frequently in naturally occurring hydrocarbon mixtures, constitutes $20.5 \%$ of the cricket hydrocarbons.

The Series III hydrocarbons constitute 59\% of cricket hydrocarbons. The 37-carbon member of this series alone constitutes $27 \%$ of the total. This series was established to consist of methylalkanes having the methyl sidechain toward the middle of the carbon chain. In fact, each homologous member of this series consists of a mixture of alkanes having the methyl side-chain at different positions in the carbon chain. This was established by collecting and submitting to mass spectral analysis the 35,36 , and 37 carbon members of the series. The mass spectra were interpreted in the same way that Mold et al. (12) interpreted mass spectra of similar hydrocarbons.

The 37-carbon homologue, with a parent peak at $520\left(\mathrm{C}_{37} \mathrm{H}_{73}\right)$, had prominent fragmentation peaks at $323\left(\mathrm{C}_{22} \mathrm{H}_{47}\right), 295\left(\mathrm{C}_{21} \mathrm{H}_{43}\right)$, $253\left(\mathrm{C}_{18} \mathrm{H}_{27}\right)$, and $225\left(\mathrm{C}_{16} \mathrm{H}_{33}\right)$. This pattern suggests that the sample is a mixture of 15methylhexatriacontane and 17-methylhexatriacontane. The major fragment ions result from cleavage of the parent ion on either side of the methyl group. There may be traces of 13methylhexatriacontane since there are slightly enhanced fragment peaks at $351\left(\mathrm{C}_{25} \mathrm{H}_{51}\right)$ and $197\left(\mathrm{C}_{14} \mathrm{H}_{29}\right)$.
The 36-carbon homologue submitted for mass spectral analysis was unfortunately contaminated with significant quantities of 35-carbon Series III alkanes. Thus the mass spectrum is less definitive than the one discussed above. Nonetheless it is informative. Prominent fragmentation peaks at $337\left(\mathrm{C}_{24} \mathrm{H}_{49}\right)$ and 197 $\left(\mathrm{C}_{14} \mathrm{H}_{29}\right)$ indicate the presence of 13-methylpentatriacontane; peaks at $309\left(\mathrm{C}_{22} \mathrm{H}_{45}\right)$ and $225\left(\mathrm{C}_{16} \mathrm{H}_{33}\right)$ indicate 15-methylpentatriacontane; and peaks at $281\left(\mathrm{C}_{20} \mathrm{H}_{41}\right)$ and $253\left(\mathrm{C}_{18}\right.$ $\mathrm{H}_{47}$ ) indicate 17-methylpentatriacontane. The 35 carbon contaminants appear to be 13methyltetratriacontane, 15-methyltetratriacontane, and 17-methyltetratriacontane.

Clearly the mass spectrum of a mixture as complex as this one is not subject to rigorous interpretation. However the absence of prominent fragmentation peaks at $155\left(\mathrm{C}_{11} \mathrm{H}_{2 \vartheta}\right)$, $183\left(\mathrm{C}_{13} \mathrm{H}_{27}\right), 211\left(\mathrm{C}_{17} \mathbf{H}_{31}\right)$, and $239\left(\mathrm{C}_{17}\right.$ $\mathrm{H}_{35}$ ) requires that no methyl branches occur on carbon atoms number $10,12,14$, or 16 in the alkane chain. Likewise the absence of any major fragment peaks above $337\left(\mathrm{C}_{9.4} \mathrm{H}_{49}\right)$ requires that no methyl group occur closer to the end of a 35-carbon chain than carbon atom number 13.

The mass spectrum of the 35-carbon Series III alkane, which is contaminated with 34 - and 36 -carbon homologues, is even more complex and less rigorously interpreted. However the pattern is the same. The mass spectrum is consistent with a mixture of 13-methyltetratriacontane (peaks at 323 and 197 owing to $\mathrm{C}_{93} \mathrm{H}_{47}$ and $\mathrm{C}_{14} \mathrm{H}_{29}$ ), 15-methyltetratriacontane (peaks at 295 and 225 owing to $\mathrm{C}_{21} \mathrm{H}_{43}$ and $\mathrm{C}_{16} \mathrm{H}_{23}$ ), 17-methyltetratriacontane (peaks at 267 and 253 owing to $\mathrm{C}_{10} \mathrm{H}_{29}$ and $\left.\mathrm{C}_{19} \mathrm{H}_{{ }_{7}}\right)$, 13-methylfritriacontane (peaks at 309 and 197 owing to $\mathrm{C}_{n n} \mathrm{H}_{45}$ and $\left.\mathrm{C}_{14} \mathrm{H}_{29}\right)$, 15-methyltritriacontane (peaks at 281 and 225 owing to $\mathrm{C}_{{ }_{0}} \mathrm{H}_{41}$ and $\mathrm{C}_{1} \mathrm{H}_{33}$ ), 17-methyltritriacontane (one peak at 253 owing to $\mathrm{C}_{18} \mathrm{H}_{37}$ ), and 13-methylpentatriacontane (peaks at 337 and 197 owing to $\mathrm{C}_{: 41} \mathrm{H}_{49}$ and $\mathrm{C}_{14} \mathrm{H}_{29}$ ).

Although the suggested composition of this mixture may be subject to debate, what the mass spectrum indicates incontestably is that there are no major fragment ions with the formulas $\mathrm{C}_{11} \mathrm{H}_{23}$ (155), $\mathrm{C}_{13} \mathrm{H}_{27}$ (183), $\mathrm{C}_{15} \mathrm{H}_{31}$ (211), and $\mathrm{C}_{17} \mathrm{H}_{35}$ (239), thus reinforcing the conclusion arrived at earlier that, in the Series III alkanes, methyl groups occur at the oddnumbered carbon atoms 13, 15, and 17 and not at the even-numbered carbon atoms 10 , 12,14 , and 16.

Hydrocarbons of this type, in which the 
methyl group is located at a carbon atom toward the center of the chain, have been identified in wool wax (12), where they comprise $4.5 \%$ of the total saturated hydrocarbons, and may have been detected in sugar cane wax (9) and in the waxes derived from three plants, Humulus lupulus, Populus nigra, and Rosa spec. $(5,6)$, but in none of these cases do they constitute the major hydrocarbon type.

The Series IV hydrocarbons, which are trace components in the 15 to 20 carbon range were not identified. They fall on the same logarithmic plot as the Series III hydrocarbons, but since no Series III or IV hydrocarbons in the 21 to 26 carbon range could be detected even as trace components, it does not seem likely that the two series are related anabolically. Besides, since the Series III alkanes have their methyl group at least 13 carbon atoms from the nearest end, no 15 or 20 carbon compound could class as a member of such a series. No attempt was made to characterize these trace constituents.

The olefinic hydrocarbon fraction constitutes $16-18 \%$ of the total hydrocarbons. The GLC of the olefin fraction clearly indicated one major and possibly two minor homologous series. Hydrogenation of the olefin mixture gave an alkane mixture composed of $n$-alkanes from 18 through 39 carbon atoms and 2methylalkanes from 22 through 39 carbon atoms. The n-alkanes made up about $67 \%$ of the hydrogenation mixture, the isoalkanes about $33 \%$. No 3-methylalkares or Series III alkanes were detectable. The major n-alkanes were $n$-nonacosane, $n$-hentriacontane, $n$-heptatriacontane, $n$-octatriacontane, and $n$-nonatriacontane. All of the isoalkanes were present in small quantities except for 2-methyldotriacontane, 2-methyltetratriacontane, and 2-methylhexatriacontane, which were the three major isoalkanes.

A mass spectrum of the hydrocarbon mixture obtained initially from the crickets had parent peaks at $544\left(\mathrm{C}_{399} \mathrm{H}_{76}\right), 530\left(\mathrm{C}_{? 8} \mathrm{H}_{74}\right)$, $516\left(\mathrm{C}_{3 i} \mathrm{H}_{72}\right), 460\left(\mathrm{C}_{33} \mathrm{H}_{6,4}\right), 432\left(\mathrm{C}_{31} \mathrm{H}_{60}\right)$, and $404\left(\mathrm{C}_{29} \mathbf{H}_{56}\right)$, indicating a prevalence of dienes. An ultraviolet spectrum of the olefin mixture had a weak maximum at $\lambda_{\max }$ of 230 $\mu(\varepsilon \sim 500$, assuming an average molecular weight of 486). Thus there is less than $5 \%$ conjugated diene present. The oxidative cleavage of the olefin mixture is informative although the complexity of the mixture precluded complete structural assignment. Straight-chain acids from 6 to 26 carbon atoms were obtained. The absence of lower acids is not significant since they would have been lost in the workup The predominant straight-chain acids were the $7,12,14,24$, and 26 carbon acids.

Methyl-substituted acids with from 20 to 26 ca bon atoms were also produced; the 22 and 24 carbon homologues predominated. Thus in the 2-methylalkadiene series it appears that urkaturation gets no closer to the branched enll of the chain than 19 carbon atoms. The struight-chain acids suggest a similar location of the unsaturation in the normal alkenes and alliadienes. A more complete structural analysis of this olefin mixture would require isolaticin of individual homologues. Alkanes and alkadienes have been isolated from a number of natural sources, but 2-methylalkenes and 2mothylalkadienes do not appear to have been reported previously.

The hydrocarbons of the crickets' food were alst surveyed. In addition to large amounts of highly branched material, probably largely ischrenoid in nature, which would not form a sollible urea clathrate compound, there was also present some material which did form a solvble clathrate. This material was almost entirely composed of n-alkanes, from n-nonadecane through n-tritriacontane. At most only traces of Series II isoalkanes were present, and none of the Series III hydrocarbons were detectable. Thus the n-alkanes in the cricket may be present as a consequence of the selective up take of dietary hydrocarbons. However the Series II hydrocarbons appear to be, and the Series III hydrocarbons most certainly are, products of anabolic hydrocarbon metabolism.

So little is known about hydrocarbon biosynthesis that it is hardly even fruitful to speculate about the origin of the cricket hydrocarbons. Long-chain fatty acids are plausible precursors. Because of the ease of raising $A$. domesticus, the ease with which radioactive fatty acids could be fed to them, and the ease with which the various hydrocarbon classes can be separated, crickets would appear to be an ideal organism for the study of hydrocarbon metabolism.

\section{ACKNOWLEDGMENT}

Supported in part by the University of Michigan Cancer Research Institute and the American Cancer Society.

\section{REFERENCES}

1. Baker, G., J. H. Pepper, L. H. Johnson and E. Hastings. J. Ins. Physiol., 5, 47-60 (1960).

2. Baker, G. L., H. E. Vroman and J. Padmore, Biochem. Biophys. Res. Commun. 13, 360-365 (1963).

3. Carruthers, W.. and R. A. W. Johnstone. Nature 184, 1131-[132 (1959). 
4. Hallgren, B., and S. Larsson, Acta Chem. Scand. 17, 1822-1824 (1963).

5. Jarolimek, P., V. Wollrab, M. StreibI and F. Sorm, Chem. Ind. 237-238 (1964).

6. Jarolimek, P., V. Wollrab and M. Streibl, Coll. Czech. Chem. Commun. 29, 2528-2536 (1964).

7. Louloudes, S. J., D. L. Chambers, D. B. Moyer and J. H. Starkey, Ann. Entomol. Soc. Am. 55, 442-448 (1962).

8. Romanuk, M., V. Herout and F. Sorm, Coll. Czech. Chem. Commun. 24, 2018 (1959).

9. Sorm, F., V. Wollrab, P. Jarolimek and M. Streibl, Chem. Ind. 1833-1834 (1964).

10. Waldron, J. D., D. S. Gowers, A. C. Chibnall and S. H. Piper, Biochem, J. 78, 435-442 (1961).

11. Mold, J. D., R. E. Means, R. K. Stevens and J. M. Ruth, Biochemistry 3, 1293-1298 (1964).

12. Mold, J. D., R, E. Means, R. K. Stevens and J. M. Ruth, Ibid. 5, 455-461 (1966).
13. Robbins, W. E., J. N. Kaplanis, S. J. Louloudes and R. W. Monroe, Ann. Entomol. Soc. Am. 53, 128-129 (1960)

14. Piek, T., J. Ins. Physiol, 10, 563-572 (1964).

15. Faurot-Bouchet, E., and G. Michel, Bull. Soc. Chim. Biol. 47, 93-97 (1965).

16. Ghouri, A. S. K., and J. E. McFarlane, Can. Entomol. 90, 158-165 (1958).

17. McFarlane, J. E., Can. J. Zool. 42, 645-647 (1964).

18. Hutchins, R. F. N., and M. M. Martin, Lipids, in press.

19. Carroll, K. K., J. Lipid Res. 2, 135-141 (1961).

20. deVries, B., Chem, and Ind. 1049-1050 (1962).

21. Chang, T. C. I., and C. C. Sweely, J. Lipid Res. 3, 170-176 (1962).

22. Metcalf, J. P., and A. A. Schmitz, Anal. Chem. 33, 363-364 (1961).

[Received July 17, 1967] 